\title{
Motor Vehicle Accidents: the Most \\ Common Cause of Traumatic Vertebrobasilar Ischemia
}

\author{
Michel Beaudry, J. David Spence
}

\begin{abstract}
Background: Recent media exposure of strokes from chiropractic manipulation have focused attention on traumatic vertebrobasilar ischemia. However, chiropractic manipulation, while the easiest cause to recognize, is probably not the most common cause of this condition. Methods: We reviewed all consecutive cases of traumatic vertebrobasilar ischemia referred to a single neurovascular practice over 20 years, from the office files and hospital records. Results: There were 80 patients whose vertebrobasilar ischemia was attributed to neck trauma. Five were diagnosed as due to chiropractic manipulation, but the commonest attributed cause was motor vehicle accidents (MVAs), which accounted for 70 cases; one was a sports injury, and five were industrial accidents. In some cases neck pain from an MVA led to chiropractic manipulation, so the cause may have been compounded. In most vehicular cases the diagnosis had been missed, even denied, by the neurologists and neurosurgeons initially involved. The longest delay between the injury and the onset of delayed symptoms was five years. Conclusions: Traumatic vertebrobasilar ischemia is most often due to MVAs; the diagnosis is often missed, in part because of the delay between injury and onset of symptoms and, in part, we hypothesize, because of reluctance of doctors to be involved in medicolegal cases.
\end{abstract}

RÉSUMÉ: Les accidents de la route: la plus fréquente cause d'ischémie vertébro-basilaire traumatique. Introduction: La couverture médiatique récente des accidents vasculaires cérébraux causés par des manipulations vertébrales a attiré l'attention sur l'ischémie vertébro-basilaire traumatique. Bien que les manipulations vertébrales soient la cause la plus facile à identifier, elle n'est cependant pas la cause la plus fréquente de cette affection. Méthodes: Nous avons revu tous les dossiers cliniques au cabinet et à l'hôpital de cas consécutifs d'ischémie vertébro-basilaire traumatique référés à la même clinique de médecine neuro-vasculaire sur une période de 20 ans. Résultats: Chez 80 patients, l'ischemie vertébro-basilaire a été attribuée à un traumatisme cervical, dont cinq cas étaient dus à des manipulations vertébrales. La cause la plus fréquente était un accident de la route, soit 70 cas; chez un cas, il s'agissait d'une blessure sportive et chez cinq autres, d'accidents de travail. Dans certains cas, des douleurs cervicales dues à un accident de la route ont motivé les manipulations vertébrales de telle sorte que, dans ces cas, la cause était peut-être mixte. Dans la plupart des cas d'accidents de la route, le diagnostic n'avait pas été fait ou avait même été écarté par les neurologues et les neurochirurgiens consultés initialement. Le délai le plus long entre le traumatisme et le début des symptômes tardifs était de cinq ans. Conclusions: L'ischémie vertébro-basilaire traumatique est due la plupart du temps, à un accident de la route; souvent le diagnostic est manqué parce que d'une part il y a un délai entre le traumatisme et le début des symptômes et d'autre part, nous présumons, à cause de la réticence qu'éprouvent les médecins à s'impliquer dans les cas médicolégaux.

Can. J. Neurol. Sci. 2003; 30: 320-325

A tragic case of chiropractic manipulation leading to stroke and death has recently put this condition again into the headlines and onto the television screens of the nation, but it is not a new problem. $^{1}$ Our experience of 80 cases of traumatic vertebrobasilar ischemia over 20 years shows that chiropractic manipulation, while important, is only the most easily recognized cause. We suspect that the frequency of this problem may be greatly underestimated, both because the diagnosis is usually only considered when the neck trauma has been recent, and because mechanisms of injury other than chiropractic manipulation may not be considered. Whiplash accidents in particular seem to evoke an avoidance response by neurologists and neurosurgeons.

Recent neck trauma has been implicated in causing several posttraumatic conditions such as extracranial carotid ${ }^{2,3}$ and

From the Department of Clinical Neurological Sciences, University of Western Ontario, London, Canada.

Received OCtober 23, 2002. ACCePTED infinAlform May 12, 2003. Reprint requests to: David Spence, Stroke Prevention \& Atherosclerosis Research Centre, Siebens-Drake Bldg., Robarts Research Institute, 1400 Western Road, London, Ontario N6G 2V2 Canada. 
vertebral dissection ${ }^{2,4}$ with subsequent infarction, post-traumatic basilar migraine $e^{5,6}$ and post-traumatic motion-induced vertigo. In recent case series it has been proposed that because of the similarity between cases of spontaneous dissection and those following even minor trauma, both may have the same pathophysiological mechanism. ${ }^{7-9}$

Dissection of the carotid and vertebral arteries has recently been reviewed; ${ }^{10}$ an important emerging concept is that genetic abnormalities of collagen, elastin and other supporting elements in the vessel wall may predispose to dissection with even minor trauma such as sneezing or Valsalva maneuvers. ${ }^{11}$

When ischemic symptoms occur some time after trauma, the connection between trauma and vascular events is more difficult to recognize. The longest described delay between trauma and onset of vertebrobasilar symptoms was two months in a fatal case of vertebral thrombosis with embolization to the basilar artery, discussed below. ${ }^{12}$ Delays of seven weeks after injury, ${ }^{13}$ and 37 days after a motor vehicle accident (MVA) have been reported for the vertebrobasilar distribution, ${ }^{14}$ and delay of many years has been described in the carotid artery distribution. ${ }^{3}$

The natural history after dissection is usually one of healing within weeks to months. The incidence of neurological sequelae after dissection is unknown because the diagnosis is difficult and can be missed. Patients may suffer only transient ischemic attacks, and when vertigo is a feature it is often difficult for the attending physician to think of cerebral vascular problem as opposed to a vestibular problem, particularly in a young patient. Another cause for confusion is migraine, which can produce visual symptoms indistinguishable from those due to transient ischemia in the posterior cerebral artery territory. Compounding this difficulty, migraine can be triggered by trauma. ${ }^{6}$

We describe a consecutive series of patients referred to one neurovascular practice over 20 years, with flexion-extension and/or rotational neck trauma. Some of these patients had immediate symptoms but in many cases vertebrobasilar symptoms occurred months to years after trauma.

\section{Methods}

This is a retrospective case series of 80 cases, including all consecutive cases diagnosed as traumatic vertebrobasilar ischemia in one neurovascular practice (JDS) over 20 years. Other cases referred as possible traumatic vertebrobasilar ischemia were excluded if JDS did not make that diagnosis.

Two severe cases, the first after chiropractic manipulation, ${ }^{15}$ the second after an MVA, were seen a few months apart, in 1977 and 1978. The first 32 cases, representing the first 10 years' experience, were reviewed by MB during his stroke fellowship; the last 10 years' experience, representing 48 cases, were reviewed by JDS. Many of these patients were seen months to years after their most severe episode. This is reflected in a delayed time to angiogram which in most cases was several years after trauma; the angiography was often done during an asymptomatic period. Later cases were studied mainly by magnetic resonance angiography (MRA). Because many of the cases in which the injury occurred in an MVA were referred by lawyers, there is an important problem with selection bias, and thus the conclusions drawn here can only be regarded as hypothesis-generating.

\section{RESUlts}

There were 80 patients whose vertebrobasilar ischemia was attributed to neck trauma. Age ranged from 13 to 74 (mean 37.2 \pm 12.5 SD.); 44 (55\%) were women. Fifty-six (70\%) cases had loss of consciousness (LOC) either at the time of the injury or with subsequent episodes of vertebrobasilar ischemia, and 51 (64\%) had some difficulty with short-term memory, or episodes of transient global amnesia. Two had sleep disturbances (one narcolepsy, the other sleep-walking) attributed to vertebrobasilar ischemia.

The mechanism of injury was varied (Table). One person was struck by a car door swinging closed as she was getting out of the car; five were chiropractic injuries, five were industrial accidents (one mining, one a bus driver struck by a paraplegic ramp during its deployment; one an assault by a patient in a home for developmentally delayed adults, one a lumberjack struck in the face by the end of a log, the other a passerby struck by a construction crane); seven were pedestrians struck by motor vehicles (one by a motorcycle), and the remainder were involved in MVAs, of which three were single vehicle accidents, four were head-on collisions, nearly half were side-impact collisions, and just over a third were rear-end collisions. Several patients (eg Case 61) had a motor vehicle accident, and then had further vascular injury by neck manipulation.

The severity of the initial trauma was substantial for some patients, but was mild for many. Eighteen had no LOC; 14 of them denied a blow to their head. Seven had brief LOC and three had LOC for about an hour. Two patients had amnesia of one and three days respectively and only one had a significant head injury; he was probably unconscious for several hours and is the only one with significant sequelae attributable to the initial blow to his head.

Soon after the trauma, sometimes with a delay of one to two hours, 22 patients complained of neck pain and 11 of headache. In follow-up, 13 complained of chronic neck pain, 5 of chronic headache and 12 of recurrent paroxysmal headaches; 10 patients had no chronic pain condition.

Four patients had recurrent symptoms provoked by movement of the head (usually rotation); the relationship of such symptoms to instability of the alar and other atlanto-axial ligaments is discussed further below (see Discussion). Readers are also referred to the information on the author's website http://robarts.ca/sparc

\section{Description of cases}

\section{Group 1. Ischemia presenting within 24 hours:}

Case 1: This woman of 33 was seen on March 1, 1977, when she developed a severe headache and a deficit evolving to a right lateral medullary syndrome with severe hypertension thought to be due to medullary ischemia with loss of CNS modulation of blood pressure. She also presented initially with transient bilateral decreased vision. The fact that she had experienced chiropractic manipulation on the night preceding her symptoms was not discovered until she was presented at the weekly intercity Grand Rounds of the Department of Clinical Neurological Sciences, and her angiograms were shown. She was also known to have menstrual migraine and a ten year history of hypertension. 
A first angiogram done in March 1977 showed occlusion of the right vertebral artery, a narrowing of the left vertebral at $\mathrm{C} 1$ 2 , and gross irregularity of the basilar artery with poor filling. A repeat angiogram in August revealed a more adequate circulation in the uninvolved portion of the basilar artery. Hematological profile including antinuclear antibody was negative. When reexamined in May 1977 she had slight hyperreflexia in the left leg with dysdiadochokinesis, and a residual Horner's syndrome. When last seen in 1980 she had had no further episodes.

Case 2: This 43-year-old woman was involved in an MVA in August of 1978, in which her car was struck from behind while she was stopped to turn left; at the moment of impact, she had her head turned to the left. She experienced severe immediate posterior neck pain high on the left side of the neck, but no immediate vertebrobasilar symptoms. The next day, while peeling carrots at the kitchen sink with her neck flexed, she experienced binocular loss of vision, vertigo, and a sense of impending LOC, leading her to sit down on the floor; the symptoms cleared in about a minute. Later the same day, while carrying a load of laundry down a flight of stairs, with her neck flexed and turned to see the stairs around the pile of laundry, she experienced binocular loss of vision, vertigo, and then lost consciousness. She came to at the bottom of the stairs, having sustained a fracture of the left distal fibula. When seen in the emergency department there were no definite residual signs of vertebrobasilar ischemia, but angiography showed delayed filling of a dominant left vertebral artery. It was, in part, the humorous aspect of the difficulty of explaining to the insurance company how a fractured leg was due to a motor vehicle accident the previous day, that made the association between MVAs and delayed vertebrobasilar ischemia easier to recognize in the subsequent cases.

\section{Group 2. Ischemia presenting after a delay:}

Case 5: This woman of 34 was injured in an MVA in February 1979 in which her small car was flattened against the side wall of a highway by a bus. She lost consciousness for two hours. On awakening in the emergency room of a hospital, she had severe neck pain with paralysis of both legs and the left arm. It was initially thought that she was hysterical or malingering, because, she was told, if her problem were a stroke it should only affect the leg ipsilateral to the affected arm. She made a slow recovery, on a psychiatry ward, still requiring a walker after six months.

In October 1984, just after struggling to pull a stuck shopping cart out of a line in a supermarket while shopping with her young daughter, she suddenly experienced a severe right sided headache associated with vertigo, diplopia and LOC. On regaining consciousness in a nearby hospital emergency room, she was aware of dysarthria, left homonymous hemianopsia, dysphagia, and numbness and paralysis of the left face, arm and leg. The hemiplegia persisted for two months. Angiography at that time showed an occlusion of the right vertebral artery at the origin, and occlusion of the left vertebral artery above the origin of posterior inferior cerebellar artery. Echocardiogram was negative. When first seen by JDS in 1985, her neurological examination revealed decreased sensation and strength of $3 / 5$ on the left side with hyperreflexia on the right side. Investigation for systemic lupus erythematosus and hypercoagulable states was negative.

Case 50: This 30-year-old man was involved in a MVA in March of 1991. His car was struck on the right side by a fuel truck at $>90 \mathrm{~km} / \mathrm{hr}$; he was found 40 feet from car. He was unconscious at the scene for a period lasting several minutes. Although he was said to have regained consciousness at the scene, he had post-traumatic amnesia for two to three weeks except for brief islands of recollection.

He had a fracture of the $\mathrm{C} 7$ facet with C6-7 subluxation, and a right $\mathrm{C} 7$ root injury. His cervical spine was stabilized with Halifax clamps. Following the accident he had ongoing problems with basilar migraine (vertigo, flashing lights, vomiting, headache), and difficulty with bladder control. He was referred to JDS in 1996 because of problems beginning with an episode in September 1995 in which he had flashing lights in his vision going on to LOC while in the shower. Subsequently he had 14 episodes of LOC some preceded by binocular visual dimming or loss; several of these episodes were followed by dysarthria. He also had three episodes of transient global amnesia, and several episodes of being lost in familiar streets and a familiar shopping mall, suggesting disturbance of visual association cortex. On examination in January 1996, he had titubation, and an old right hemiparesis with a right inverted supinator sign. Cerebral angiography in January 1996 showed occlusion of the right vertebral artery at C6-7, with reconstitution distally by collaterals, and sluggish flow. He was treated with warfarin, and on that therapy has remained free of vertebrobasilar ischemic episodes through to his last follow-up on April 24, 2001.

\section{DisCUSSION}

These 80 cases represent all consecutive cases in one neurovascular consulting practice over 20 years, in which symptomatology was attributed to traumatic vertebrobasilar ischemia. During that time, but not included here, a large number of other patients were seen with migraine including

Table: Characteristics of the patients $(n=80)$

\begin{tabular}{|c|c|c|c|c|c|}
\hline & MVA & Pedestrian & Chiropractic & Industrial accident & Sports injury \\
\hline Mechanism of injury (n) & 62 & 7 & 5 & 5 & 1 \\
\hline \multicolumn{6}{|l|}{ Overall group: } \\
\hline Age 13-74 & $37.2+12.5$ & & & & \\
\hline Sex & $55 \%$ female & & & & \\
\hline Loss of consciousness & $70 \%$ & & & & \\
\hline Memory problems & $64 \%$ & & & & \\
\hline
\end{tabular}


vertebrobasilar symptomatology, or vertebrobasilar ischemia attributed to other causes (atheroembolic, athero-occlusive, cardiac emboli). Two cases of carotid dissection after chiropractic manipulation were seen, in addition to other carotid dissections without chiropractic manipulation.

An important concern is referral bias, since many of the patients were referred by lawyers.

Even if all the cases referred by lawyers are excluded from analysis, MVAs still remain as the most common cause of this syndrome, roughly six-fold more common than chiropractic manipulation.

We have been struck by how often neurologists and neurosurgeons miss or refuse to recognize the diagnosis, and suspect that it is often dismissed because of an aversion to medicolegal cases and legal practitioners. This aversion may be natural, given the contrast between the caring, cooperative nature of medicine, and the hostile, adversarial nature of the legal system. The unwillingness to diagnose this condition of traumatic vertebrobasilar ischemia in the setting of MVAs is in marked contrast to the willingness, even eagerness, to diagnose it in the setting of chiropractic manipulation, often by the same physicians who are unwilling to recognize it in MVA cases. The contrast between these situations highlights the subjective nature of diagnosis; we are willing to consider diagnoses that fit our biases and experience, and until aware of this syndrome, physicians are unlikely to diagnose it.

Paroxysmal vertigo usually precipitated and aggravated by sudden movement seems to be as frequent after whiplash injury as after head trauma. Two-thirds of our patients were so affected. When associated only with nausea or ataxia, paroxysmal vertigo was not attributed to ischemia. It seems likely in many cases that infarction of the vestibular nucleus or its connections may lead to subsequent movement-induced vertigo as a consequence of the initial event; such episodes do not implicate repeated episodes of cerebral ischemia.

One recurrent theme in the extensive notes of other physicians and surgeons that have seen the patients in whom ongoing difficulty with an amnestic syndrome is a feature, is that the focus is often on diffuse brain injury, when the actual head injury was trivial; we speculate that vertebrobasilar ischemia, once considered, is a much more likely explanation. A clue to the vascular etiology in these cases is that the duration of posttraumatic amnesia, often days, is greatly out of proportion to the observed duration of LOC. Typically, the ambulance attendants or emergency room staff will record that the patient is conscious (though sometimes confused), but the patient has little or no recollection of the trip to the hospital, the visit to the emergency room, the trip home, and even the first several days after arriving home. Such a picture suggests an amnestic syndrome (analogous to a prolonged episode of transient global amnesia), due to ischemia in the mesial temporal lobes bilaterally, rather than diffuse brain injury, which would be expected to result in a longer duration of initial unconsciousness to be severe enough to cause post-traumatic amnesia of such a duration.

The syndrome should be suspected when the patient has a neck injury which, in many cases, may be minor, and subsequently develops symptoms in the brainstem, cerebellum, occipital lobes, and inferior mesial temporal lobes. No other structure or system connects those parts of the brain, other than the vertebrobasilar arterial system and its distal runoff in the posterior cerebral arteries. With respect to subsequent episodes of LOC, ischemia in the brainstem, affecting the reticular activating system, is a more likely cause of LOC, than global ischemia of both hemispheres. When the LOC is preceded by binocular visual symptoms, localized to the occipital lobes, and vertigo, localized to the pons, or other symptoms that localize to the brainstem, there is no other reasonable explanation. In considering this diagnosis, it is important to heed the admonition of Osler, to make the parsimonious diagnosis that will explain all the patient's manifestations.

Another manifestation of brainstem reticular formation disturbance that we have seen is sleep disturbances. One patient, Case 59, experienced striking sleepwalking episodes, including one in which she woke up naked, locked out of her hotel room; she had no previous history of sleep disturbances. Another patient, Case 47, developed narcolepsy, which has previously been described as a post-traumatic disorder. ${ }^{16}$ In previous posttraumatic cases, shearing injury to the brainstem reticular formation has been invoked; in these cases it seems more likely that ischemia in the reticular formation is the cause.

The diagnosis is often missed, in many cases because the neck injury is a minor event such as a chiropractic manipulation, and may not be mentioned at the time of presentation, as in our Case 1. Another reason for failure to consider the association between the neck injury and the subsequent vertebrobasilar ischemia is the delay in time; when the event occurs immediately after the trauma, the association is hard to miss, but delay causes the association to be regarded as less probably causal. As our cases 4 and 50 illustrate, the delay can be up to four and nearly five years respectively, so it seems likely that exclusion on the basis of delay causes many cases to be missed.

\section{Mechanism of injury}

With extension of the neck, especially when adding a rotational component, the vertebral artery is stretched and/or compressed in the foramen transversarium of the atlas or before it pierces the atlanto-occipital ligament.

Trivial neck turning such as looking backward while backing up a car $^{4}$ or during swimming, yoga or archery $^{2}$ have been implicated. Recently a case of postpartum dissection of the vertebral artery was described; ${ }^{17}$ the mechanism of injury was likely the arching of the neck during contractions; it is possible that a Valsalsva maneuver may have contributed.

Caplan et $\mathrm{al}^{15}$ have described cases of postoperative vertebrobasilar ischemia that we suspect were related to neck extension during intubation; the authors attributed them in many cases to "positioning" during surgery. We suspect that in our Case 64, a man who was sleeping in the back of a station wagon and was ejected 50 yards forward through the windshield, the vertebral artery injury at the site of the $\mathrm{C} 1$ fracture was precipitated or aggravated by extension of the neck during endotracheal intubation, since the nurses' notes first record manifestation of vertebrobasilar ischemia several hours after the patient was intubated in the intensive care unit; he also was intubated earlier in the operating room for his lifesaving surgery.

Weintraub $^{16}$ described a group of patients in whom vertebrobasilar ischemia came on after extension of their necks over the edge of a hairdresser's sink while having their hair 
shampooed. Using MRA, they have shown that rotation and extension of the neck obstructs flow in a dominant vertebral artery. ${ }^{18}$ These patients, like our Case 69 , may be predisposed to the problem by virtue of a dominant vertebral artery on one side, and poor collaterals through the posterior communicating arteries.

The question of delay calls for discussion of pathophysiologic mechanisms. It is believed that initial tearing of the intima leads to progressive dissection and, if not immediate occlusion, a narrowing of the lumen with later occlusion in some. It is also implied that local thrombosis leads to distal embolization. A case series of traumatic dissection of the carotid artery included four cases with delayed symptomatology of more than three years between trauma and symptoms. ${ }^{3}$ Occlusion or thromboembolism complicating the dissection was the proposed mechanism. Viktrup et $\mathrm{al}^{12}$ described a case of fatal basilar thrombotic embolus two months after a whiplash accident; autopsy revealed a thrombus in the right vertebral artery, with a thrombotic embolus in the basilar artery. Our Case 50 appears to have had a similar event, with embolization distal to the occlusion of his vertebral artery at C7, the level of his vertebral subluxation.

Rare presentations, not seen in our series, include osteophytes compressing a vertebral artery with recurrent transient ischemic attack events. ${ }^{19}$ Relief after surgical decompression has been demonstrated in isolated case reports.

Since most people (72\%) have an asymmetric circulation, ${ }^{20}$ with a substantial proportion having one hypoplastic vertebral artery, neck turning toward the normal side might produce symptoms especially if a new lesion reduces reserve capacity, as demonstrated by Weintraub and Khoury using MRA. ${ }^{18}$

Another important mechanism is posttraumatic atlanto-axial dislocation with $\mathrm{C} 1$ sliding on $\mathrm{C} 2$ with bilaterally compromised circulation. ${ }^{21,22}$ Our cases 47, 58 and 68, who had episodes of vertebrobasilar ischemia provoked by turning of the head, were found by a physiotherapist and a physician with training in physical methods to have instability of the alar or other atlantoaxial ligaments. Our Case 69 had repeated episodes of vertebrobasilar ischemia brought on by turning of her head, including one in which she dropped her baby, apparently because of central cord syndrome (the anterior spinal artery in the high cervical cord receives its supply from the vertebral arteries before they join to form the basilar), as described by Schneider et $\mathrm{a}^{21,22}$ in football players with neck hyperextension and rotation due to face-mask injuries.

Another possible mechanism for production of symptoms is vasospasm, based on data on subarachnoid bleeding after experimental whiplash injury ${ }^{23}$ and the high frequency of post whiplash neck stiffness. A phenomenon rarely described in the literature is the delayed pathology seen in a vessel previously in spasm. A pathological study demonstrated that the vertebral system is much more prone to develop chronic changes, reflecting prior spasm, than the anterior system. ${ }^{24}$ Histological analysis revealed subendothelial thickening with medial necrosis reminiscent of changes seen after subarachnoid hemorrhage. We reason that these changes might go unnoticed if the patient is asymptomatic and likewise, because the thickening is diffuse and circumferential, might go undetected in the angiogram.

A likely mechanism for some of our patients'transient events is migraine. A prior history of migraine or family history, a known risk factor for post-traumatic migraine, was rarely found in our patients (three cases). Winston ${ }^{25}$ has described five patients with whiplash injury and later characteristic vascular headache. One of his patients developed binocular silver dots two days post trauma and visual blurring in her left eye one month post trauma. On the other hand, monocular symptoms are characteristic of the entity described under the term of "cervicogenic headache" by Sjaastad. ${ }^{26}$ Jacome $^{5}$ has described four patients similar to some of our patients. These patients presented, months to years after a whiplash injury, with episodes of posterior throbbing headaches, visual blurring, near syncope in two, vertigo, various dysesthesias and transitory motor signs. A good response to drug therapy for migraine, including dramatic response to phenytoin, was characteristic.

A variant associating neck trauma with transient global amnesia has been described. This occurs within minutes of the trauma ${ }^{27-29}$ but one patient presented other episodes delayed by weeks and months, and another had a brother with a similar history of transient global amnesia induced by a mild blow to the head. ${ }^{29}$ Another strong point for migraine is the site of involvement in many of these patients, which is the upper basilar and bilateral posterior cerebral artery, the latter the arteries par excellence for migraine. ${ }^{30-32}$

\section{Future directions}

We suggest that angiography (perhaps by magnetic resonance or CT angiography) be performed as early as possible after vertebrobasilar transient ischemic attack. Treatment with an antiplatelet agent, although not demonstrated to improve prognosis, should probably be given. In cases of basilar occlusion, bilateral vertebral occlusion, such as Cases 4 and 70, or sluggish flow in the vertebrals (Cases 2 and 50) long-term anticoagulation may be advisable.

Further investigation should make use of noninvasive methodology such as MRI/MRA and Doppler, ${ }^{33}$ done within a few days of whiplash injury, as part of a longitudinal follow-up.

Another issue that may require further exploration is the issue of instability of the ligaments in the atlanto-axial junction. It seems likely that there is more to learn about how to protect such patients from repeated compromise of their vertebrobasilar supply with movement of the neck. Vinchon et $\mathrm{al}^{34}$ reported a case of traumatic atlanto-axial instability in whom vertigo brought on by angiographically-demonstrated occlusion of the vertebral artery with neck rotation was relieved by atalanto-axial fusion. One of our patients whose symptoms are provoked by neck movement has gone on to surgical fixation at the C1-2 level because of ongoing symptoms; another is being considered for surgery.

With MRA or ultrasound it is possible to do prospective studies in patients with neck injury; we recommend that such studies be carried out to clarify the relationship between neck injury and vertebrobasilar ischemia.

Traumatic vertebrobasilar ischemia may present up to four and nearly five years after the neck injury. It is, therefore, probably much more common than is currently suspected. Though chiropractic manipulation is perhaps the best-known cause, it is important to recognize that MVAs are a much more common cause, which is often missed. We hypothesize that reluctance of neurologists and neurosurgeons to recognize this 
entity in the setting of MVA may be due to avoidance of the legal system.

Because many of the cases in which the injury occurred in an MVA were referred by lawyers, there is an important problem in this case series with selection bias, and thus the conclusions drawn here can only be regarded as hypothesis-generating.

\section{REFERENCES}

1. Jeret JS, Bluth M. Stroke following chiropractic manipulation. Report of 3 cases and review. Cerebrovasc Dis 2002; 13(3):210213.

2. Hart RG, Easton JD. Dissections of cervical and cerebral arteries. Symposium on cerebrovascular disease. Philadelphia: W.B. Saunders, 1983: 155-182.

3. Mokri B, Piepgras DG, Houser W. Traumatic dissections of the extracranial internal carotid artery. J Neurosurg 1988; 68:189197.

4. Sherman DG, Hart RG, Easton JD. Abrupt change in head position and cerebral infarction. Stroke 1981; 12:2-6.

5. Jacome DE. Basilar artery migraine after uncomplicated whiplash injuries. Headache 1986; 26:515-516.

6. Haas DC, Lourie H. Trauma-triggered migraine: an explanation for common neurological attacks after mild head injury. Review of the literature. J Neurosurg 1988; 68:181-188.

7. Bogousslavski J. Dissections of the cerebral arteries: clinical effects. Curr Opin Neurol Neurosurg 1988: 63-68.

8. Mas JL, Bousser MG, Hasbourn D, Laplane D. Extracranial vertebral artery dissections: a review of 13 cases. Stroke 1987; 19:1037-1047.

9. Caplan LR, Zarins CK, Hemmati M. Spontaneous dissection of the extracranial vertebral arteries. Stroke 2002; 16:1030-1038.

10. Scievink WI. Current Concepts: Spontaneous Dissection of the Carotid and Vertebral Arteries. N Engl J Med 2001; 344:898-906.

11. Mayer SA, Rubin BS, Starman BJ, Byers PH. Spontaneous multivessel cervical artery dissection in a patient with a substitution of alanine for glycine (G13A) in the 1(I) chain of type I collagen. Neurology 1996; 47:552-556.

12. Viktrup L, Knudsen GM, Hansen SH. Delayed onset of fatal basilar thrombotic embolus after whiplash injury. Stroke 1995; 26:21942196.

13. Auer RN, Krcek J, Butt JC. Delayed symptoms and death after minor head trauma with occult vertebral. J Neurol Neurosurg Psychiatry 1994; 57(4):500-502.

14. Nichelli P, Gibertoni M, Guerzoni C. Delayed cerebellar infarction following a car accident. Stroke 1983; 14:617-619.
15. Tettenborn B, Caplan LR, Sloan MA, et al. Postoperative brainstem and cerebellar infarcts. Neurology 1993; 43:471-477.

16. Weintraub MI. Beauty parlor stroke syndrome: report of five cases. JAMA1993; 269:2085-2086.

17. Van de Kelft E, Kunnen J, Truyen L, Heytens L. Postpartum dissecting aneurysm of the basilar artery. Stroke 1992; 23:114-116.

18. Weintraub MI, Khoury A. Critical neck position as an independent risk factor for posterior circulation stroke. A magnetic resonance angiographic analysis. J Neuroimaging 1995; 5:16-22.

19. Caplan LR. Vertebrobasilar occlusive disease. In: Barnett HJM, Mohr JP, Stein BM, Yatsu FM, (Eds). Stroke. Pathophysiology, Diagnosis, and Management. New York: Churchill, Livingstone, 1986: 570 .

20. Stopford JSB. The arteries of the pons and medulla oblongata. J Anat 1916; 50:131-164

21. Schneider RC, Crosby EC. Vascular insufficiency of brain stem and spinal cord in spinal trauma. Neurology 1959; 9:634-656.

22. Schneider RC, Gosch HH, Norrell H, et al. Vascular insufficiency and differential distortion of brain and cord caused by cervicomedullary football injuries. J Neurosurg 1970; 33:363-375.

23. Ommaya AK, Faas F, Yarnell P. Whiplash injury and brain damage. JAMA1968; 204:285-289.

24. Hughes JT. Morphological changes in human cerebral arteries in relation to intracranial arterial spasm. I. In: Wilkins RH, (Ed). Cerebral Arterial Spasm. Baltimore, London: Williams \& Wilkins, 1979.

25. Winston KR. Whiplash and its relationship to migraine. Headache 1987; 27:452-457.

26. Sjaastad O, Saunte C, Hovdalh H, et al. "Cervicogenic" headache. An hypothesis. Cephalalgia 1983; 3:249-256.

27. Haas DC, Ross GS. Transient global amnesia triggered by mild head trauma. Brain 1986; 109:251-257.

28. Fisher CM. Whiplash amnesia. Neurology 1982; 32:667-668.

29. Hofstad H, Gjerde IO. Transient global amnesia after whiplash trauma. J Neurol Neurosurg Psychiatry 1985; 48:956-957.

30. Fisher CM. Unusual vascular events in the territory of the posterior cerebral artery. Can J Neurol Sci 1986; 13:1-7.

31. Olesen J, Larsen B, Lauritzen M. Focal hyperemia followed by spreading oligemia and impaired activation of $\mathrm{rCBF}$ in classic migraine. Ann Neurol 1981; 9:344.

32. Bogousslavski J, Regli F, Van Melle GV, et al. Migraine stroke. Neurology 1988; 38:223-227.

33. Thie A, Spitzer K, Lachenmayer L, Kunze K. Prolonged vasospasm in migraine detected by noninvasive transcranial Doppler ultrasound. Headache. 1988 Apr;28(3):183-186.

34. Vinchon M, Assaker R, Leclerc X, Lejeune JP. Vertebrobasilar insufficiency resulting from traumatic atlantoaxial instability: case report. Neurosurgery $1995 ; 36: 839-841$. 